\title{
Factors of Black Humor Popularity
}

\author{
Nikolay N. Gubanov \\ Bauman Moscow State Technical University \\ $5 / 1,2$ nd Baumanskaya St. \\ Moscow, Russia 105005 \\ E-mail: gubanovnn@mail.ru
}

\author{
Nikolay I. Gubanov \\ Tyumen State Medical University \\ 54 OdesskayaSt. \\ Tyumen, Russia 625023 \\ E-mail: gubanov48@mail.ru
}

\author{
Ludmila Rokotyanskaya \\ Bauman Moscow State Technical University \\ 5/1, 2nd BaumanskayaSt. \\ Moscow, Russia 105005 \\ E-mail: lo_rokotyanskaya@ rambler.ru
}

\begin{abstract}
Black humor is the most ambiguous kind of humor, able to awaken in a person a whole range of emotions and feelings - shock, disgust, shame, joy. What is black humor? How is it different from other types of humor? What factors affect the success or social failure of a black joke? Here is a list of questions which we have tried to answer in this paper. Based on the results of "disaster humor" studies, we have also considered the media influence in the perception formation of black humor public death and popularity growth. Particular attention is paid to the effect of multiple repetition of the sametype information, which, even in the case of socially significant problems, pushes society first to indifference and then to laughter. In cases of especially painful topics for a person such as the theme of death, black humor can serve a protective reaction from excessive repetition of emotionally painful information.
\end{abstract}

Keywords—black humor; disaster humor; psychological distance; mass media; trolling; public death; private death

\section{INTRODUCTION}

What is black humor? According to the tradition that goes back to Andre Breton, the author of the first anthology of black humor, most researchers refrain from attempts to give a clear definition to the term. On the other hand, it is perhaps the only kind of humor that defines itself. There are a number of jokes that serve as something of an understanding identifier:

"Black humor is like food - not everyone gets it.

"Black humor is like a pair of legs - not everyone has it.

"Black humor is like a kid with cancer - never gets old.

Indeed, black humor "does not age", as it touches on the most taboo topics relevant to all times and peoples: death and violence, serious diseases and physical deformities, sexual deviations and discrimination. Since the second half of the twentieth century, tragedies and catastrophes have been added to the list of topics, which have been widely publicized in the media, such as famine, earthquakes, terrorist attacks, mass murders, plane crashes and even the death of celebrities.

Black humor - is the line that we hesitatingly still crave to step across. A successful black joke often causes a mixture of feelings - shock, disgust, shame, and, of course, joy. This is not the type of humor, which we are in a hurry to share with an unfamiliar person. Is he ready to step across line? And is he ready to step over it with us? If the usual humor signals an attempt to convergence, the transition to a more friendly level of communication, the black humor is much more intimate - it is comparable with a secret handshake.

Black humor is a matter of taste. Some people like it more, some-less. We can even assume that there are whole nations and generations of people more than others disposed to the black humor - this will certainly characterize the mentality of this social group $[1,2]$. On the other hand, all modern culture is saturated with black humor today. Thus, to some extent, each of us at least once laughed at black jokes. After all, elements of black humor are present even in the classical children's literature. For example, "he ran along the path and he was cut the legs..."("Aibolit" byKorneyChukovsky). The famous "Bad tips" also serve as a good example of black humor for children and their parents ("If the whole family went to swim to river, /do not disturb your dad and mumlying in the sun./ Don't make noise,/ let the parents have a rest./ Don't bother anyone,/ try to drown").

It is also worth noting that black jokes, which half a century ago were "semi-legal" nameless folklore, today they have their own specific authors-famous comedians, presenters, screenwriters, directors, authors of comic books. However, even the professionals make mistakes in the use of this type of humor. For example, American comedian Gilbert Gottfried at one of his performances decided to tell a joke about the terrorist attack, despite the fact that since the tragedy of September 11thhad only been about three weeks. 
The public reaction was negative - Gottfried heard indignant cries "Too soon!"

When is it not early? How long does it take for the tragedy to be funny? And what are the success factors of a black joke?

In the animated series "South Park", which touch on the theme of AIDS, a comic answer to this question is given the cartoon characters claim that "the tragedy becomes ridiculous when 22 years and 3 months pass." Exactly so much time had passed since the discovery of AIDS before the release of this series. Surprisingly, this answer has the color of reason, though it is a joke.

\section{FACTORS AFFECTING THE PERCEPTION AND ASSESSMENT OF BLACK HUMOR}

American psychologists A. Peter McGraw, Caleb Warren, Lawrence Williams, analyzing the dynamics of jokes about hurricane "Sandy", found the parameters that affect the perception and evaluation of black humor. According to the researchers, "psychological distance" plays a critical role in forming a humorous reaction to a tragic event. In the concept of "psychological distance" they included the following four components: temporal distance, spatial distance, social distance and hypothetical distance [3].

Let us consider in more detail each of these types of distance.

- Temporal distance: Time is perhaps the first and most obvious parameter. We all know that "time heals." Mark Twain's idea that" humor is a tragedy plus time" was repeated by many famous comedians. Thus, time is the most important component of the black humor success.

The more time has passed since these or other tragic events, the more positive the jokes about them are perceived. However, this conclusion seems to be valid only for black humor. As A. Peter McGraw, Caleb Warren, Lawrence Williams found out, in the case of small failures, everything is quite the opposite - the fresher the event is, the better jokes about it are perceived. For example, the story of how someone cutting his finger will be funnier, the less time has passed since the cut [3].

- Social distance: it is more pleasant to joke about what happened not with us. To demonstrate the essence of this statement, A. Peter McGraw and his colleagues cite the comedian Mel Brooks: "The Tragedy is when I cut my finger. Comedy is when you fell into an open manhole and broke your neck" [3].

- Spatial distance: the farther we are from the scene of the tragedy, the easier we can joke about it. The impact of geographical distance A. Peter McGraw and his colleagues are investigating on the example of the reaction to jokes about hurricane Sandy. The farther from the respondents a hurricane was, the better they perceived humor about it.

- Hypothetical distance: a fictional humorous story is perceived better than a real one [3].

Black humor, not tied to a particular tragedy or personality, has a better chance of success. Indeed, "tear off the head" of a toon is much easier - both from a technical and from a psychological point of view. Perhaps it is in this, not in immaturity, a love of contemporary adults to cartoons lies. Cartoons allow you to achieve the desired level of abstraction, i.e. unreality, what creates an ideal base not only for children but also for adult humor. Moreover, the abstraction degree of the humorous character gives an additional advantage in the perception of black humor.

If we turn to the Soviet "sadistic poems" or the American "cycle of jokes about dead babies", telling about /narrating about unexpected children's deaths, we will find that the heroes of both cycles are abstract, faceless, almost inanimate objects: "little boy", "little girl", in the American version - just "baby". Constantly recurring death of a faceless "little boy" is present in the popular animated series "South Park". In each series a boy Kenny dies in the most ludicrous way: Ozzy Osbourne bites off his head for sake of epatage; the police shoot him when he goes to them with a white flag; he is hit by an ambulance; he is pecked to death by turkeys; and in one of the series he even dies of laughter. At the same time, it is worth noting that Kenny is the least disclosed character. The only thing that's known about him is that he's poor. The character's speech is also poorly distinguishable, due to the hood that covers almost all his face. That is, as in the case of "sadistic poems", Kenny - is all the same abstract "little boy". On the one hand, the level of abstraction is much lower - after all, Kenny has a name, appearance, parents, friends. On the other hand, the absurdity and grotesqueness of the events happening with Kenny is much higher, i.e. more irreal, which greatly facilitates the perception of black humor. In general, the popularity of the child mortality subject in black humor is a curious topic for a separate study.

Thus, according to the study of A. Peter McGraw, Caleb Warren, Lawrence Williams, the joke about the tragic event that happened not with us (social distance), at the other end of the world (spatial distance), long ago (temporal distance) and not actually (hypothetical distance) has more chances of success with the public.

Without denying the fact of influence of the listed parameters on black humor perception degree, we note that in case of so-called "hangman humor" none of the listed distances find sits necessity. Thus, the Austrian psychiatrist, Victor Frankl, talking about his stay in the Nazi concentration camp, draws attention to the particular black humor popularity in the prisoners: "So, the illusions collapsed one after another. And then there was something unexpected: black humor. We knew we had nothing to lose, but the ridiculously naked body" [4, p. 125]. Apparently, in the conditions creating a crisis in the human psyche, 
thinking can independently create all the distances necessary for humor - to distance ourselves from ourselves, from the place which we are in and the fact that the ridiculed case is real and happens with us [5].

\section{INFORMATION REPEATABILITY}

What else, in addition to these parameters, can affect the formation and popularity of black humor? A. Peter McGraw, Caleb Warren, Lawrence Williams also note the relationship between "psychological distance" and abstract thinking. Black humor is characterized by the shift of attention focus from a specific interpretation of the event to an abstract one [3]. What is the trigger for such a transfer? Apparently, the inclusion of abstract thinking is facilitated by the repeatability of the same type of information.

This pattern can be traced in the formation and functioning of the so-called "disaster humor". We are talking about a rather ambiguous form of humor based on real tragedies. It has appeared relatively recently and, according to most researchers, is associated with the media role in too active coverage of tragic events.

For the first time on the media role in the black humor development one began to talk in the late 80 -ies of the last century. Five weeks after the explosion of the space Shuttle Challenger, jokes about the disaster began to spread throughout the country. Shuttle launch was broadcast live. The very fact of the emergence and active spread of such humor caused shock and great interest from scientists. The main reason for the popularity of jokes about the disaster was too active and detailed coverage of the tragedy in the media. The audience could be said to be "bombarded" with the disaster scenes-the Shuttle explosion recording repeated in the news again and again [6].

Active "disaster humor" dissemination continued also in the twenty-first century. The terrorist attacks of 11th September have contributed to a large number of jokes, and the Internet has made them easier to spread around the world. However, this time the "disaster humor" did not remain only at the level of folk Internet forums, but came to the level of mainstream media in the form of night TV shows, stand-up comedies, concerts and cartoons. In this case there revealed another trend in the development of black humor - the transition from the impersonal folklore to jokes of specific comedians.

The hypertrophied coverage influence of disasters by media on black humor development is also noted by $\mathrm{W}$. Phillips in her book on trolling. As an example, she considers the phenomenon "RIP-trolling" - the publication of blasphemous images or comments on Facebook pages dedicated to the dead. Since 2009, Facebook has provided an opportunity to perpetuate the accounts of the deadfriends and relatives could write on the wall of the deceased. Facebook's initiative was also actively supported by leading media outlets: "Lisa Miller, from Newsweek, commented enthusiastically on these changes, saying that "this is how we collectively mourn: Globally. All together. Online"" [7, p. 118]. Such a sensation led to the beginning of active trolling. RIP-pages of people whose deaths were covered in detail in the media were under greatest fire. The more subscribers were, the stronger and tougher trolling in response was: "The use by trolls the most "black" or in any other way deducing from the balance aspects of a particular tragedy demonstrates the media tendency to focus on "black" and disturbing details. In other words, trolls could exploit certain details because these details were chosen for media coverage. <...> If once mill of gossip and detailshad stopped, the trolls would have stopped at the same second. But the mill continued to grind the details, and the trolls continued to troll" [7, p. 137-138]. Moreover, trolling was turned primarily to "necro-tourists" - people who express their condolences, but have nothing to do with the deceased [8].

Thus, "disaster humor"can be seen as a revolt against tragedy escalation, as well as against the way journalists cover events, looking for the slightest "delicious" details.

"Disaster humor" researchers also drew attention to the existence of two completely different degrees of experience: "public death" and "private death" [6]. A common element of this humorous genre is the appeal to the personalities that the public knows only through the news of the disaster. But at its core they are strange, media, personalities. Before the disaster, we knew nothing about them, so we cannot experience public tragedies as much as our personal ones. The tragedy victims and their families are presented by journalists as people for whom and with whom the whole country should mourn. However, the excessive tragedy escalation activates the protective mechanisms of the psyche.

Any information repeatability, even in relation to socially important themes, ultimately leads to indifference.

The more news reports about the same events (such as, for example, military actions in Ukraine or daily terrorist attacks in Baghdad), the more it becomes all the same [9]. The same applies to charity events that are now haunting us everywhere: volunteers on the streets, ads on television and social networks. The endless list of people in need of help children, cats, dogs, lonely pensioners - is so great and inexhaustible that calls for charity do not cause anything but indifference. There is a lack of empathy-too many people need help, and the chain of suffering does not end. The French philosopher Henri Bergson was right-humor opposes any "mechanistic". All that is constantly repeated is the best candidate for ridicule. H. Bergson writes: "Let's note further such not less worthy attention a sign as insensitivity accompanying usually laughter. Apparently, comic can only have an impact if it touches a completely calm, balanced soul. Indifference is its natural environment. Laughter does not have stronger enemy than experience" [10, p. 8]. Thus, in cases of particularly painful themes for a human - such as the theme of death-humor may seem to be a protective reaction to the excessive repetition of emotionally painful information.

The general increase in popularity of black humor, which began around the end of the 19th-the beginning of the 20th centuries, may be due to the fact that modern news blocks (whether television or Internet sources) are literally saturated with the theme of death, usually sensational and 
sudden [11]. The theme of death in the large flow of everyday information is very extensive. However, it is perceived as something routinely-daily. Only in the case of a private death, you can suddenly "wake up" and pay attention to the number of posts, reports and articles on death. And all this is against the background of the modern people specific attitude to death. Instead of the words "died" or "dead" we use intricate metaphors: "gone to the next world", "no longer with us", "God rest his soul". Not informational but real death is literally pushed out of our lives. The French historian Philippe Arièsin his work "Man in the teeth of death" writes that in the cities it is literally not noticeable. Even modern hearses are not different from ordinary cars and are invisible in the general traffic flow. Nothing breaks the working rhythm. It seems that people do not die at all. But it wasn't always so. Philippe Arièscomes to the conclusion that, at least since the Early Middle Ages, the way people treated death has changed greatly: "In former times death was part of the daily risk. Since childhood, it has been more or less expected. A man of the distant past did not expect much from life, as our contemporary. "The Lord gave, and the Lord hath taken away" was a life formula"[12, p. 477].

Thus, at least in the economically developed countries of the West, death is often mentioned, but still unreal, far. It is this combination that creates fertile ground for producing black humor - repeatability and a significant level of abstraction/unreality.

The influence of repeatability on the humor production (especially parodies and jokes), is also noticeable in the sphere of cinema. Thus, the production of a large number of template horror films has led to the creation of the horror Comedy film genre.

Despite the fact that horror films began to appear almost simultaneously with the cinema advent, full-scale including commercial success of this genre fell on the 70-80-ies of the twentieth century. It was at this time that such iconic films appeared as "The Exorcist" (1973), "The Texas Chain Saw Massacre"(1974), "The Omen" (1976), "Carrie" (1976), "The Hills Have Eyes" (1977), "Halloween" (1978), "Friday the 13th" (1980), "The Shining" (1980), "A Nightmare On Elm Street" (1984). These films have laid down certain patterns, and even templates for further genre development. In the following decades, a wide thematic variety of horror films was created, as well as their remakes and sequels: "Wrong Turn" (6 films), "Final Destination" (5 films), "Scream" (5 films), "The Grudge" (6 films), "Saw" (8 films) and many others.

The horror film plot element repeatability as in the case of excessive exaggeration of the death theme in the media, has led to the emergence of numerous parodies of the abovementioned and many other horror films: "The Scary Movie" (2000), "The Scary Movie 2" (2001), "The Scary Movie 3" (2003), "The Scary Movie 4" (2006), "The Scary Movie 5" (2013).

The influence of the same type of horror films on the production of black humor is also noticeable in the prank genre. Today, pranking is understood as a video recording of a prank posted on the Internet on the video hosting website. The most popular pranks belong to black humor genre. The authors of these pranks often use the terrible images generated by horror movies - video jokes in which a maniac with a chainsaw or an evil clown with a sledgehammer hunting for passers-by became Youtube hits. The purpose of the prank is seen to scare to death a passerby, and then let him know that in fact he "bought" the stereotypical creepy image.

The so-called refrain - repetition of the same scene several times in a row-is a favorite method of professional comedians and screenwriters. According to the same principle on which a Comedy film refrain is based, emotionally rich information repeated many times, gradually (over time) loses its emotional charge, becoming an abstract idea (the idea of the "Holocaust", the idea of "11thSeptember", the idea of "terrorist attack", the idea of "a little boy death ", etc.) around which a black joke is built [13].

Repeatability of your own thoughts, apparently, also leads to the mockery effect. Long experience on any occasion passes into the category of an idea around which derogatory humor is built, as well as the "hangman humor" mentioned earlier. Many comedians joke about depression and suicide. And this is not surprising because for many of them this theme is close and understandable. List of professional comedians who openly declare their protracted depression, bipolar disorder, thoughts of suicide is impressive: Robin Williams, Stephen Fry, Woody Allen, Richard Pryor, Jim Carrey, Rowan Atkinson, Ben Stiller, Hugh Laurie and many others.

\section{CONCLUSION}

Finally, what is the difference between black humor and any other humour? After all, even in the classical Comedy scene with a falling man there is an element of "blackness" - we laugh at those who are hurt. However, we understand that this is not serious that a person will get up, shake himself off and go on. And even if he took his lumps, as it is said, it'll be OK till the wedding day. This humor is normal. Black humor contains an element of irreversibility: one cannot bring back the dead, the terminally ill patient will not be cured, the severed limb will not grow as in the case with lizards. Apparently, the physical damage scale described in a joke affects how it will be evaluated by the public and categorized. It is possible that if someday in the future prostheses not distinguishable from natural extremities are created or, even better, humanity achieves immortality, then black humor will cease to be black. At the present time, black humor serves to transform the tragic events of our life into abstract ideas. The abstract idea is abstracted from the events that occurred and reduces the psycho-traumatic perception of real phenomena. Thus, black humor fulfills the function of psychological defense. 


\section{REFERENCES}

[1] Gubanov N.I., Gubanov N.N.Mentality: the nature and functioning in society // Voprosyfilosofii. 2013. № 2. P. 22-32.

[2] Gubanov N.I., Gubanov N.N. The role of mentality in the development of society: sociocultural hypothesis // Vestnikslavianskikh kultur-bulletin of slavic cultures-scientific and informational journal. 2017. Vol. 43. № 1. P. 38-51.

[3] McGraw A.P., Warren C., Williams L.E. The Rise and Fall of Humor: Psychological Distance Modules Humorous Responses to Tragedy.Social Psychological and Personality Science, 2014, vol. 5, no. 5, pp. 566-572.

[4] Viktor E. Frankl. TrotzdemJazumLebensagen.1984, Viktor E. Frankl Published by arrangement with the Estate of Viktor E. Frankl.[In Russ.: Frankl W. Say life "Yes!"Psychologist in the concentration camp. Moscow, Alpina Non-fiction, 2015].

[5] Nekhamkin V.A. A counterfactual Challenge of the Past: Ways of Negotiation // Herald of the Russian Academy of Sciences. 2017. Vol 87. Issue 2. P. 191-198. DOI: 10.1134/S1019331617020046

[6] Smyth W. Challenger Jokes and the Humor of Disaster. Western Folklore, 1986, vol. 45, no.4, pp. 243-260.

[7] Whitney Phillips. This is why we can't have nice things. The MIT Press, Cambridge, Massachusetts, London, England. [In Russ.: Phillips W. Trololo: You can not just take a book about trolling.Moscow, AlpinaPablisher, 2016, 300 p.].

[8] Oseledchik M.B., IvlevV.Yu., Ivleva M.L. Using social networks in knowledge management system //Proceedings of the 2nd International Conference on Culture, Education and Economic Development of Modern Society (ICCESE 2018). Moscow, Russia. Pp.911-914.

[9] Suzdaleva T.R. Migratory processes in the context of geopolitics // VestnikTomskogogosudarstvennogouniversiteta-Filosofiya-

sotsiologiya-politologiya-Tomsk state university journal of philosophy sociology and political science. 2016. № 3 (36). P. 237244. DOI: $10.17223 / 1998863 X / 35 / 25$

[10] Henri Bergson "Le Rire", 1940. [In Russ.:Bergson H. Laughter.Moscow, Iskusstvo Publ., 1992.

[11] Zemtsov B.N. Right as World Outlook Value of the Power (XX Century) // Tomsk State university journal of history. 2014. № 4 (30). P. 28-34.

[12] Ares F. The Man in the Face of Death. Moscow,Publishing group "Progress" - "Progress-Academy", 1992.

[13] Oseledchik M.B., IvlevV.Yu., Ivleva M.L. Knowledge as a nonequilibrium dynamic system // "Proceedings of the 2017 2nd International Conference on Contemporary Education, Social Sciences and Humanities". (ICCESSH 2017). Part of the series ASSEHR. Moscow, Russia. V/124. P.1-5. 